\title{
M-Learning: Focus on Digital Fluency
}

\author{
https://doi.org/10.3991/ijac.v13i2.17195 \\ Patricia Alejandra Behar ${ }^{(凶)}$, Tássia Priscila Fagundes Grande, \\ Anna Helena Silveira Sonego, Sibele Pedroso Loss \\ Federal University of Rio Grande do Sul, Porto Alegre, Brazil \\ patricia.behareufrgs.br
}

\begin{abstract}
The present article deals with the creation of a pedagogical architecture (PA) to assist teachers and students in their development of digital fluency through mobile learning. For this we chose a qualitative case study approach, in a distance education discipline for students of different graduate courses from a university in southern Brazil. As concluding actions, we found that the application of the created PA can help in the planning and development of activities that foster digital fluency through m-learning, expanding the possibilities of the teaching and learning processes of students in the distance modality.
\end{abstract}

Keywords-Pedagogical architectures, digital fluency, mobile learning, teaching and learning processes.

\section{Introduction}

The goal of the present article is to create a pedagogical architecture (PA) to assist in the development of digital fluency through m-learning. We believe in the relevance of creating this PA in order to support and guide teachers who intend to develop activities that contemplate the use of mobile devices in distance education (DE).

It is important to note that we are witnessing the growing use of Information and Communication Technologies (ICT), both in daily life and in the educational context. As it can be seen in the survey on the use of information and communication technologies in Brazilian households [1], smartphone-type mobile phones appear in the first position as the most used way to access the internet (92\%), followed by the laptop (29\%), and the tablet (16\%). This way, we understand that the computer is not the main technological resource, and that portable devices, such as tablets and smartphones, have the preference among the population. One of the factors that make the population prefer mobile devices is the fact that these devices are small, making their transportation easier and they have all the technological resources present on computers. The shift from computer to mobile devices is related to how fast technology advances. In this sense, smartphones and tablets are considered mobile devices, which have functions similar to those of a common computer, but with the differential of mobility [2]. Currently, tablets and smartphones have as many tools and features as a computer, as well as internet access, but they have the advantage of 
being lighter and easier to carry around. Thus, education can benefit from using online tools and technological resources accessible to the population by mobile devices and not only computers.

We understand that, with the integration of ICT in education, there were changes, mainly in distance education in relation to communication and interaction. According to Mill [3], Moore and Kearsley [4], DE is characterized by students and teachers in different locations throughout the whole course or during most of it. In other words, as they are physically distant from each other, they depend on communication technologies to interact. Therefore, we consider that mobile devices have features that allow teachers and students on distance learning to research new possibilities and use them in teaching and learning as a way to expand communication, interaction and information sharing. In addition, they may be able to minimize the distance between those involved in these processes. In this sense, Behar et al [5] state that "the role of ICT is to contribute to 'reduce' this 'pedagogical distance,' ensuring forms of communication and interaction between the 'actors' involved in the process of knowledge building in distance education." Thus, the teaching and learning planned and organized by the teacher may reduce the distance between the subjects involved.

The activities carried out in DE should be planned in order to promote knowledge building and the use of mobile devices may contribute with it. However, it should be clear that using these means alone does not guarantee effectiveness and innovation in learning processes. Therefore, having a PA in a distance learning discipline can enhance the combination of the use of these technologies with the pedagogical proposal of the course. According to Behar et al [5], a PA is supported by four elements that make up its structure, namely: 1) Organizational Aspects; 2) Content; 3) Methodological Aspects and 4) Technological Aspects. In this sense, teachers can use the elements of a PA to plan their teaching activities involving m-learning.

According to UNESCO [2], m-learning enables and facilitates communication, interaction and networking anywhere and anytime. Thus, we understand the importance of this competence so that students and teachers can have greater availability and accessibility in distance learning through mobile devices. In truth, it is expected that the actors of distance education feel as dynamic participants in the wake of technological advances [6]. Therefore, we believe that this PA aims to show the possibilities of using mobile devices, in this case, smartphones and tablets, as mediators in the teaching and learning processes of students, improving their digital fluency.

Given what was said so far, we present the organization of this text. It is divided into five sections. In the first one, the concepts of Pedagogical Architecture and Distance Education are described. The second section discusses the development of digital fluency focusing on mobile learning. In the third one, the methodological procedures of the elaboration of the pedagogical architecture are explained. In the fourth section, the results of our study are presented and, in the fifth and last section, we bring the final considerations. 


\section{Pedagogical Architecture for Distance Education: Concepts and Elements}

PA planning should consider the teaching modality and the target audience of each subject. Behar [5] defines PA as a system of theoretical premises that represent, explain and guide the way in which the curriculum is approached and that is embodied in the pedagogical practices assumed and, in the teacher, -student-object of study/knowledge interactions. This way, we consider relevant that teachers understand the reality of their students to feel able to develop strategies, using technologies and mobile devices, to contribute to the teaching and learning processes.

The PA in the present study was created for an undergraduate course at a Public University in the state of Rio Grande do Sul, Brazil. This way, this PA seeks to contribute to students through the presentation of possibilities of using mobile devices as mediators in the teaching and learning processes in distance education. We try to minimize the distance between the actors of the educational processes, making learning more contextualized.

This PA consists of the four aspects detailed below:

1. Organizational aspects: These are related to planning, organization of time and space, pedagogical expectations and proposals, objectives, actors, target audience and teaching;

2. Content aspects: These are related to teaching materials, resources and study activities;

3. Methodological aspects: These are the forms of communication and interaction, and the evaluation procedures;

4. Technological aspects: Here we choose a virtual learning environment and the hypermedia tools.

For Behar [5], a PA requires strategies to give dynamism at the moment of putting it into action, as well as allowing it to adapt the proposed architecture to the context in which it is inserted. In this sense, an architecture can be considered a resource that aims to provide innovation in teaching practices focused on distance education. Likewise, it aims to provide teachers with challenging, interactive and problematic opportunities, aiming to generate imbalances and (re)building of knowledge from the elements that make up a PA.

So, we understand that, to apply the pedagogical proposals for this discipline in distance education, it is necessary to list the competences that students need to develop, such as autonomy, reflexion, organization, communication, time management, teamwork, motivation and digital fluency. In this context, the competence of digital fluency through the use of mobile devices will be enhanced, because it is directly related to the proposal of the discipline that involves the production of content and the creation of digital educational materials with different tools. 


\section{$3 \quad$ M-Learning Focus on Digital Fluency}

For the development of activities with m-learning, it is necessary to use mobile devices such as smartphones and tablets. They enable the creation of the conditions to strengthen the training of the necessary competences for the students, according to the elements of the PA and the strategies to be used.

According to Behar [7], competences are formed by a set of conditions, elements and resources necessary for a given situation. In this sense, Zabala and Arnau [8] define competencies as the abilities to perform a task or the knowledge to deal with a problem appropriately in a given context.

Behar [7] states that competencies are formed by a set composed of knowledge (C - knowledge), skills (H - ability) and attitudes (A - being), which make up the acronym CHA.

In this context, Perrenoud [9] defines knowledge as the subject's knowledge, i.e., that it is related to the contents that will be addressed by the teacher. Skills are considered as the subject's action using this knowledge and, according to Moretto [10], they are related to practical activities, such as knowing how to carry out an action. Finally, attitudes are the "mental model of the subject, his values and beliefs". According to Behar [7], p. 29) they are closely related to a subject's intentions regarding a given situation.

The competency elements must help to solve a new problem or situation in different time and contexts. In this case, new situations may be linked to the digital fluency competency for m-learning to overcome challenges with the use of mobile devices.

Table 1. CHA of Digital Fluency Competence with focus on M-Learning

\begin{tabular}{|c|c|c|}
\hline \multicolumn{3}{|c|}{ Competency: Digital Fluency for m-learning } \\
\hline Knowledge (knowledge) & Skills (ability) & Attitudes (being) \\
\hline $\begin{array}{l}\text { - Knowing how to use mobile } \\
\text { devices and applications for } \\
\text { educational purposes; } \\
\text { - Knowing how to create } \\
\text { applications } \\
\text { - Improving your own knowledge } \\
\text { about m-learning. }\end{array}$ & $\begin{array}{l}\text { - Using mobile devices and apps } \\
\text { - Innovate and strategize using } \\
\text { mobile devices in the classroom }\end{array}$ & $\begin{array}{l}\text { - Being autonomous } \\
\text { - Being reflective } \\
\text { - Being a researcher } \\
\text { - Being proactive } \\
\text { - Having an ethical posture }\end{array}$ \\
\hline
\end{tabular}

To this end, the digital fluency competence for distance learning is seen in this study as the use of technologies related to the creation and development of educational materials, such as applications, and also the development of activities [7]. In addition, subjects may improve them throughout their lives as the needs arise as ICT progresses.

In this context, we consider it important to develop a specific competence focused on the use of mobile devices. That is why we propose the competence of digital fluency focusing on m-learning. This is understood as the use of mobile devices with emphasis on the creation of didactic-pedagogical materials. 
The identification of knowledge, skills and attitudes assist in the development of the digital fluency competency focusing on m-learning in distance education. Table 1 shows the CHA elaborated for a discipline that is $100 \%$ at a distance, with no proximate classes, and composed by students from undergraduate courses in different areas.

The use of mobile devices promotes faster communication and facilitates the interaction, as they have various features and Internet connectivity. As a result, the number of users of these devices has been growing considerably. In this context, it is important that education, its practices and its actors are updated and in line with this contemporary scenario. Thus, the CHA excels for the use of mobile devices and their tools for the creation of educational content, such as educational applications. In addition, we believe that an m-learning PA can contribute to the development of a digital fluency competency. We also understand that an architecture can favor the improvement of knowledge, skills and attitudes such as decision making and the initiative to research and become familiar with a certain theme. In the following section we will present the methodology of our research.

\section{$4 \quad$ Methodology}

In our study, we used a qualitative case study approach. To this end, we based ourselves on Yin [11], who defines this methodology as a type of research that refers to contemporary phenomena, facts and events that are part of our daily lives. The same author $(2015$, p. 27) mentions that [...] "The differentiating power of studying is its ability to deal with a wide variety of evidence, documents, artifacts, interviews and observations". To this end, a case study approach allowed the implementation of a pedagogical architecture for distance education, with the goal of assisting in the development of digital fluency through the use of mobile devices, using a specific application.

The target audience was formed by undergraduate students of various different courses from a Brazilian public university. Data collection was performed in 2019/2, in a semi-presential, elective discipline. For this, we planned three proximate meetings and twelve at a distance. The target audience of this work was 30 undergraduate students aged 19 to 40 years.

The course was conducted in a distance-learning manner with its activities mediated through a virtual learning environment (VLE), in this case ROODA, for posting activities and for interactions in forums and message exchange. In addition, there were three proximate classes. The first was for the initial presentation (schedule, activities, teachers and monitors), the second to present the technological tool used in the discipline and the third for the closing of the course, with the presentation of the final activity. To this end, a PA was created for this discipline with the use of an application. The goal was to expand the possibilities of information and communication of the discipline among those involved in it. For data analysis, the following instruments were used: participant observation and questionnaire with open and closed questions. The data allowed the analysis of the PA according to the 
following categories: organizational aspects, content aspects, technological aspects, methodological aspects and the analysis of the application as to its usefulness and relevance in the discipline. In the next section, we present the results about the creation of this PA.

\section{$5 \quad$ Analysis and Results}

After the implementation of the PA developed for a distance learning discipline focusing on the use of mobile devices in the classroom, we verified the necessary components to compose a CHA. In Figure 1 we present the aspects and elements associated with the digital fluency competence focused on m-learning and its respective knowledge, skills and attitudes (which were already presented in Table 1.)

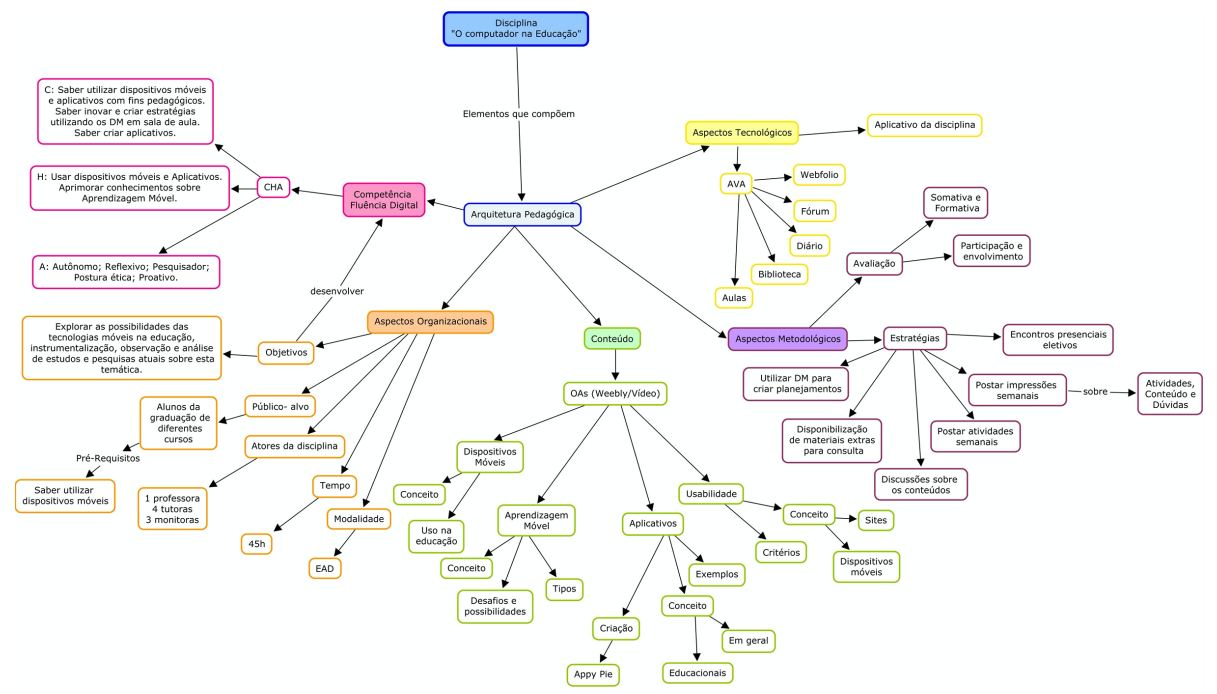

Fig. 1. Pedagogical architecture for a distance learning discipline

For its evaluation, we considered all the productions, the participation in activities, the involvement, the commitment and the punctuality in handing tasks to the teacher.

On Table 2, we show the organizational, content, methodological and technological aspects and the digital fluency competence.

Organizational aspects: Here we outlined the objectives, actors, target audience, time, discipline modality and competence development. The objectives of the PA were to explore the use of mobile devices in education, instrumentalize students, provide observation and analysis of our current research on the subject. In addition, the PA also aimed to promote the enhancement of the digital fluency competency related to the use of technologies and the creation and (re)use of content, so that the teacher and the students feel capable of performing the proposed activities. 
In this sense, we believe that the knowledge, skills and attitudes needed to build such a competency can be developed from the activities proposed to students shown in Table 2.

Table 2. Activities Developed To Improve The Digital Fluency Competence With Focus On M-Learning

\begin{tabular}{|l|}
\hline \multicolumn{1}{|c|}{ Activities } \\
\hline App analysis \\
\hline Forum and logbook discussion \\
\hline Creation and research activities \\
\hline Creation of: \\
An app \\
Lesson plans \\
Strategies \\
Videos
\end{tabular}

We consider that these activities were relevant to the development of this competence, considering that students should know how to use, create and improve tasks with the use of mobile devices, and interact with other students of the discipline.

Content aspects: These were divided into four themes: mobile devices, m-learning, applications and usability. The main concepts related to each of these themes were discussed, as well as their relation to education.

Methodological aspects: These refer to the action strategies developed in order to communicate, interact and evaluate students. In this context, we sought to promote reflexion and discussions on the proposed contents, proposing weekly activities and evaluated the participation and involvement of students throughout the course. In addition, three proximate meetings were planned, two of them to present the tools that students could use to create an educational application (the activity planned for the course). The third meeting was intended for the presentations of the final tasks. These meetings were elective in nature, and attendance could not be required due to the course being at a distance in nature, but they were designed to meet possible difficulties in developing more specific activities. Similarly, in order to promote greater understanding of the classes, each week the students were sent messages presenting the content and activities. Thus, we sought to specify how the activity should be performed, from the tools that could be used in each task in a virtual learning environment.

Technological aspects: These refer to the features used in AVA Rooda. This environment was developed to meet the demands of teachers and also of students. Each teacher can select the tools that best fit their work methodology, such as Logbook, Portfolio, Classes, Forum, Library, and others. Therefore, it is a place on the Internet where students, monitors and teachers can interact using different forms of communication. This meets the nature of the discipline (a distance learning one), generating communicability, sending messages and alerting students of activities and clarifications through the app of the discipline. Feedback on the discipline will be given through tools available in the AVA. 
Besides considering the important elements to create a PA, we also had to consider the relevance of creating pedagogical strategies. They are relevant because they give movement to the PA and allow adjustments during the course. Given this, a strategy employed in the PA was the creation of an application for the discipline. The "Computer in Education 2019/2" application, illustrated in Figure 2, presents a structure with seventeen tabs that cover the fifteen classes (one on each tab), the presentation of the discipline and the teaching staff. In addition, it made it easier and streamlined student access to classroom content via mobile devices, without the need for Internet use after the installation. The app also has the ability to send notifications to students regarding the release of lesson content every week and reminders of the deadlines of activities to be posted on the AVA.

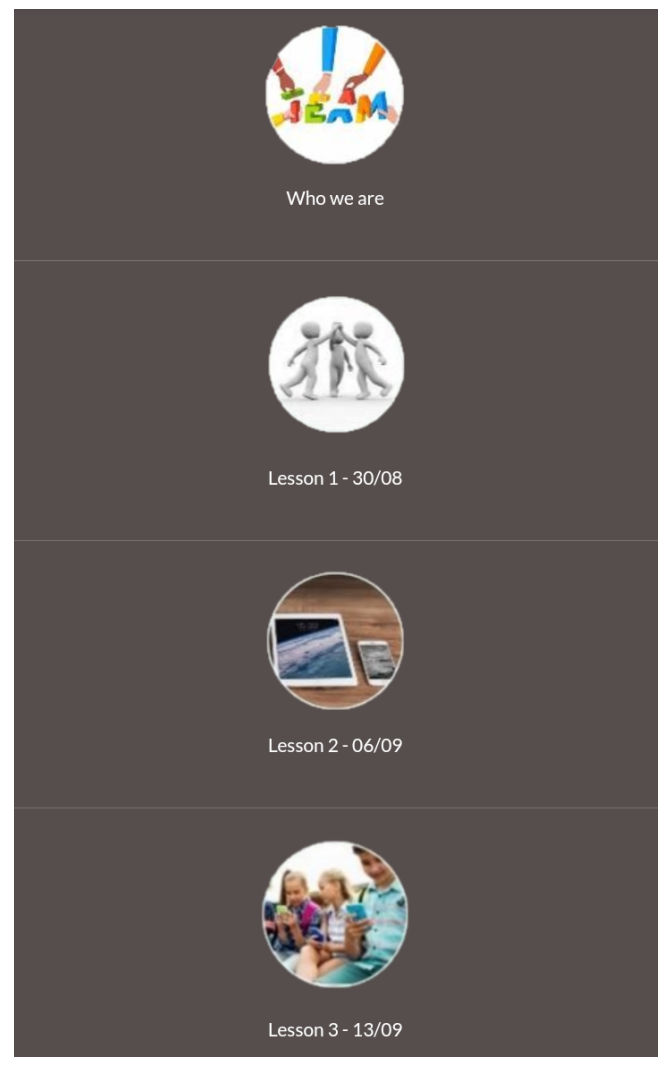

Fig. 2. App splash screen

In each tab, the activity of the week was described, accompanied by extra reading material (Figure 3).

The pedagogical strategies were presented using different forms of mobile devices and applications for education, which can be adopted by the teacher in order to promote mobile learning in the classroom. 
The application tabs can be accessed in the order they are presented or nonlinearly, that is, following the students' wishes, meeting their specific needs.

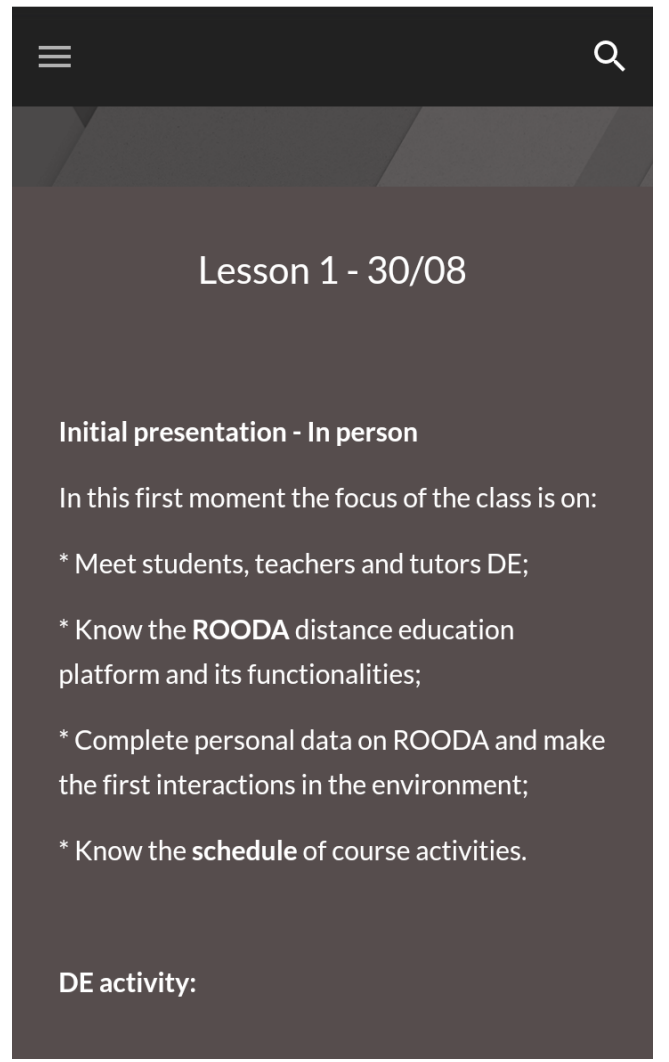

Fig. 3. First Class tab

A questionnaire showed that the students, despite accessing the application, still have the habit of checking information and activities through the discipline's virtual page. This can be seen in Figure 4. 

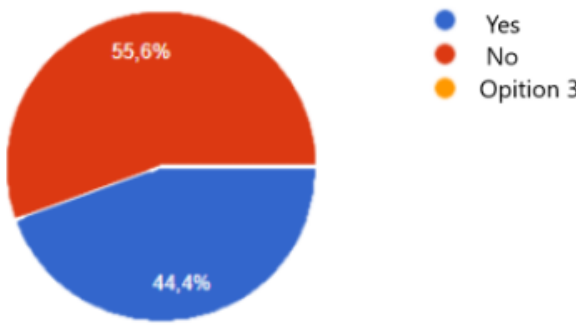

Fig. 4. Usage of the course app

It is clear that students access the application to view weekly activities, information and schedule, but it cannot yet be considered as the only source of information. The reason may be related to the fact that the discipline's activities should be posted in the VLE. Given this, we noted that they are more accessed via the site, which contains the same information as the application, but is integrated with Rooda.

In this context, we understand that the creation of a PA may enable teachers with conditions for the creation of methods, means and procedures. Thus, new forms of organization arise for the teaching and learning processes, giving support to the development of student knowledge. Therefore, it can be said that the methodological and technological aspects do not just determine techniques, procedures and computer resources to be planned and implemented in class; they are directly related to the structure that joins all these elements. Thus, it allows the implementation of architectures and strategies outlined in a situation involving didactic virtualization.

\section{Conclusion}

In this study, we presented a discussion about the concepts of a pedagogical architecture for distance education in order to provide opportunities for the development of a digital fluency competence for m-learning.

For this, it was necessary to plan and implement a PA to assist teachers and students to develop a digital fluency competence through the use of mobile devices. In this sense, the elaboration of an architecture becomes relevant to guide and encourage teachers who wish to perform activities with MD in distance learning courses.

Throughout the course, tasks such as application creation, lesson plans, strategies, video, application analysis, forum discussion, and logbook discussion were provided. They are believed to have enabled the development of digital fluency competency for m-learning through the use of mobile devices.

We understand that PA planning requires defining its aspects and developing digital fluency competence. This will happen through the accompaniment, the didactic 
material, the accomplishment of the proposed activities, the active participation of the students, among other elements.

For this article, it was necessary to understand the concept of digital fluency focused on m-learning, through the activities planned and implemented in the course through AVA Rooda and the main elements to be developed by the students enrolled in the course. Therefore, it was necessary to go through the building or improvement of the knowledge, skills and attitudes that constitute this competence. Thus, the main elements were the exploration and experimentation of tools for the creation of educational materials. Similarly, we sought to provide situations for overcoming challenges, pointing possibilities in their teaching practices, generating episodes for didactic-methodological innovations in the teaching and learning process.

Thus, it is clear that the development of a digital fluency competence focused on $\mathrm{m}$-learning is relevant, considering that among the features of mobile devices, one of the most used are apps. However, it is necessary to understand how to use them in teaching and learning, especially in distance education. We believe that an application can help in the organization and availability of materials according to ease of navigation, expanding the ways to access content, activities and information on the discipline through the use of mobile devices.

\section{$7 \quad$ References}

[1] Comitê Gestor Da Internet No Brasil. TIC Domicílios 2017 (2018). Pesquisa sobre o uso das tecnologias da informação e comunicação nos domicílios brasileiros [livro eletrônico] São Paulo. https://doi.org/10.17771/pucrio.acad.28527

[2] UNESCO. "Policy Guidelines for Mobile Learning”. Publicado pela Organização das Nações Unidas para a Educação, a Ciência e a Cultura (UNESCO), 7, place de Fontenoy, 75352 Paris 07 SP, France (2013). A tradução para o português desta publicação foi produzida pela Representação da UNESCO no Brasil. Disponível em: http://www.unesco.org/new/pt/brasilia/about-this-office/singleview/news/diretrizes de politicas da unesco para a aprendizagem movel pdf only/\#.V Z5E0vgju1E $>$.E:\IAOE2020 \iJAC \iJAC132\}

$<$ http: \www.unesco.org $\backslash$ new $\backslash p t \backslash$ brasilia $\backslash$ about-this-office $\backslash$ singleview $\backslash$ news $\backslash$ diretrizes de politicas da unesco para a aprendizagem movel pdf only $\backslash$ $\underline{\text { VZ5E0vgju1E }>\text {.https }}$ ://doi.org/10.5212/praxeduc.v.12i2.0017

[3] Mill, D. (2018). Dicionário crítico de educação e tecnologias e de educação a distância. Papirus. 736p.

[4] Moore, M.; Kearsley, G. (2013). "Educação a Distância: Sistemas de aprendizagem Online". São Paulo: Cengage Learning.

[5] Behar, P. A. (Org.), (2009). Modelos Pedagógicos em Educação à Distância. Porto Alegre: Artmed.309p.

[6] Scheneider, D.; Silva, K. K. A.; Behar, P.A. (2013). Competências dos atores da educação a distância: professor, tutor e aluno. In: Behar, P. A. (org.). Competências em Educação a Distância. Porto Alegre: Penso, Grupo A. P. 152-173. https://doi.org/10.15448/ $\underline{\text { 2179-8435.2014.2.17803 }}$ 
[7] Behar, P. A. (Org.) (2013). Competências em educação a distância. Porto Alegre: Penso. 312 p. https://doi.org/10.15448/2179-8435.2014.2.17803

[8] Zabala, A.; Arnau, L. (2010). Como aprender e ensinar competências: uma proposta para o currículo escolar. Porto Alegre: Artmed. 198 p.

[9] Perrenoud, P. (2001) Por que construir competência a partir da escola? Desenvolvimento da autonomia e luta contra as desigualdades. Porto: ASA.

[10] Moretto, V. P. (2002). Construtivismo: a produção do conhecimento em aula. 3, Ed. Rio de Janeiro: DP\&A.

[11] Yin, R. K. (2015). Estudo de Caso: planejamento e métodos. $3^{\mathrm{a}}$ ed. Porto Alegre: Bookman Companhia Ed.

\section{Authors}

Patricia Alejandra Behar is Full Professor at the Faculty of Education and Postgraduate Courses in Education (PPGEdu) and in Informatics in Education (PPGIE) at the Federal University of Rio Grande do Sul, and Visitor Professor by the Fulbright Program at the Teachers College at Columbia University (2018-2019). She has a Research Productivity scholarship (DT / Cnpq), level I. Mestre (1991-1993) and Ph.D. (1994-1998) in Computer Science from the Federal University of Rio Grande do Sul. She has experience in the Education area, with emphasis in Distance Education (EAD) and Informatics in Education. She coordinates the Digital Technology Center applied to Education (NUTED / Cnpq) of the Faculty of Education (FACED) and linked to the Interdisciplinary Center for New Technologies in Education (CINTED), since 2000. She developed the ROODA virtual environment, used as one of the platforms of Distance Learning from UFRGS in classroom and distance learning courses. She is a member of the IFIP (International Federation for Information Processing) Technical Committee 3-Education; author of the books, "Pedagogical Models in Distance Education," ArtMed: Porto Alegre, 2009, "Distance Education Skills," Porto Alegre, 2013, and "Pedagogical Recommendation in Distance Education," Porto Alegre, 2019; winner of the CAPES Prize for Tese Edition 2012 in the Interdisciplinary area, as an advisor; member of the National Science for Education Network; and co-author of one of the thematic documents Socioemotional Skills, Metacognition and Educational Technology, 2016. Porto Alegre, Brazil, (e-mail: pbehar@terra.com.br).

Tássia Priscila Fagundes Grande is a Ph.D. student in Education by the Graduate Program in Education (PPGEDU) of the Federal University of Rio Grande do Sul, in the line of research in Informatics in Education; Master in Education from the Graduate Program in Education (PPGEDU) of the Federal University of Rio Grande do Sul, in the line of research in Informatics in Education; Specialist in Psychopedagogy and Information and Communication Technologies at the Federal University of Rio Grande do Sul; and graduated in the Pedagogy Degree course at the Federal University of Rio Grande do Sul. She has experience as a classroom / virtual 
teacher and classroom / virtual tutor in the area of Education, acting mainly on the following themes: computer in education, face-to-face / virtual monitor, social networks, digital inclusion for the elderly, usability on mobile devices aimed at the elderly public and multiplying senior cybers in distance education. Porto Alegre, Brazil (e-mail: tpri.fagundes@gmail.com).

Anna Helena Silveira Sonego is a Postdoctoral fellow in the Graduate Program in Informatics in Education (PPGIE/ UFRGS); Ph.D. in Education from the Faculty of Education (FACED / UFRGS), in the research line Digital Technologies in Education (2019); researcher at the Digital Technological Nucleus applied to education (NUTED / UFRGS) since 2015; Master in Education, by the Graduate Program in Education (PPGE / UFSM, 2014), in the research line School Practices and Public Policies; graduated in Agriculture: Agroindustry from the State University of Rio Grande do Sul (2009); graduation in Teacher Education for Professional Education from the Federal University of Santa Maria (2010) and Specialization in Information and Communication Technologies applied to education (2011) by the same institution; with interest in research in the following areas: teaching and learning process mediated by digital technologies in education, convergence between educational modalities, mobile learning, teacher training and architectures and pedagogical strategies for education, especially for mobile learning. Porto Alegre, Brazil (e-mail: sonego.anna@gmail.com).

Sibele Pedroso Loss is a Post-Graduate Student in Specialization in Early Childhood Education at Faculdade Dom Alberto, and graduated in Pedagogy from the Federal University of Rio Grande do Sul. She has experience in the area of research in education, working mainly on the following subjects: information technology in education, pedagogical practices, distance education and information technology for the elderly. She acts as a teacher of Early Childhood Education in the municipal network of Viamão, Brazil (e-mail: sibeleloss@gmail.com).

Article submitted 2020-07-21. Resubmitted 2020-08-15. Final acceptance 2020-08-17. Final version published as submitted by the authors. 